\title{
Editorial: Deep Carbon Science
}

\author{
Dawn Cardace ${ }^{1 *}$, Dan J. Bower ${ }^{2}$, Isabelle Daniel ${ }^{3}$, Artur lonescu ${ }^{4,5}$, Sami Mikhail ${ }^{6}$, \\ Mattia Pistone ${ }^{7}$ and Sabin Zahirovic ${ }^{8}$
}

${ }^{1}$ Department of Geosciences, University of Rhode Island, Kingston, RI, United States, ${ }^{2}$ Center for Space and Habitability (CSH), University of Bern, Bern, Switzerland, ${ }^{3}$ Univ Lyon, Univ Lyon 1, ENSL, CNRS, LGL-TPE, Villeurbanne, France, ${ }^{4}$ Faculty of Environmental Science and Engineering, Babes-Bolyai University, Cluj-Napoca, Romania, ${ }^{5}$ Department of Physics and Geology, University of Perugia, Perugia, Italy, ${ }^{6}$ School of Earth and Environmental Sciences, University of St Andrews, St Andrews, United Kingdom, ${ }^{7}$ Department of Earth Sciences, Franklin College of Arts and Sciences, University of Georgia, Athens, GA, United States, ${ }^{8}$ Earth Byte Group, School of Geosciences, The University of Sydney, Darlington, NSW, Australia

Keywords: carbon, geology, tectonics, biosphere, volcanism, geodynamics, volatiles, carbon cycle

\section{Editorial on the Research Topic}

\section{Deep Carbon Science}

Our understanding of the slow, deep carbon cycle, key to Earth's habitability is examined here. Because the carbon cycle links Earth's reservoirs on nano- to mega-scales, we must integrate geological, physical, chemical, biological, and mathematical methods to understand objects and processes so small and yet so vast. Here, we profile current research in the physical chemistry of carbon in natural and model systems, processes ongoing in the deepest portions of planets, and observations of carbon utilization by the deep biosphere. The relationships between the carbon cycle and planetary habitability are undeniable, forming a conceptual anchor to all work in deep carbon science.

Carbon minerals respond to changing pressures, temperatures, and geochemical conditions. The geologic record preserves evidence of transitional periods at the submicroscopic to regional landscape scales, and demonstrates interplay between carbon-bearing phases and the biosphere. In a new review, Morrison et al. (2020) cast a retrospective look through deep time and call for emerging approaches to clarify the coevolution of the biosphere and geosphere.

Critical to transformations of Earth's carbon inventory over time are indomitable tectonics - which

Edited and reviewed by:

Carmen Sanchez-Valle,

University of Münster, Germany

*Correspondence:

Dawn Cardace

cardace@mail.uri.edu

Specialty section:

This article was submitted to Earth and Planetary Materials, a section of the journal Frontiers in Earth Science

Received: 28 September 2020 Accepted: 23 October 2020

Published: 12 November 2020

Citation:

Cardace D, Bower DJ, Daniel I, Ionescu A, Mikhail S, Pistone $M$ and Zahirovic S (2020) Editorial: Deep

Carbon Science.

Front. Earth Sci. 8:611295.

doi: 10.3389/feart.2020.611295 influence Earth's surface environment, weathering, metamorphism, magmatism, and volcanism. The slow, deep (endogenous) carbon cycle refines and re-distributes carbon within Earth. In fact, over the 200million-year-long time scale, important tectonic controls on carbon cycling emerge (Wong et al., 2019). Wong et al. (2019) document the spatiotemporal evolution of fluxes inferred from plate tectonic reconstructions, and highlight $\mathrm{CO}_{2}$ fluxes from continental rift settings post-Pangea. The volcanic flux of $\mathrm{CO}_{2}$ has been successfully reconstructed by direct study of $\mathrm{CO}_{2}$ flux through lakes and adjacent soils (Hughes et al., 2019), an important and often overlooked $\mathrm{CO}_{2}$ valve linking lithosphere, atmosphere, and hydrosphere. From perspectives rooted deeper in the tectonic system, the important roles that serpentinites play in the carbon cycle are evaluated in two senses: 1) serpentinite as a carbon vector to the deep mantle (Merdith et al., 2019), and 2) serpentine mud volcanoes as sites of carbon mobilization through organic acid release (Eickenbusch et al., 2019), in a Mariana Trench case study.

The physical properties of carbonaceous melt extraction and chemical exchange are experimentally examined as reduced metallic Fe-C melts (Dong et al., 2019) and oxidized carbonate melts (Sanloup et al., 2019b-note corrigendum). Regarding carbon-bearing metallic melts in the mid-mantle, Dong et al. (2019) apply experimental data to predict immobility of metallic carbon, meaning deep Fe-C melts will remain isolated in a silicate rock. Sanloup et al. (2019a) experimentally determine the density, structure and glass-forming ability of Fe-carbonate melt $\left(\mathrm{FeCO}_{3}\right)$ in the mid- to lower-mantle, and find that carbon becomes fully four-fold coordinated and the melt highly viscous, hence largely unreactive in the deep lower mantle. Both studies show deep carbon to be immobile and unreactive, under the conditions of their experimental designs. 
Linking geological and biological aspects of carbon cycling reveal emerging challenges. The drawdown of atmospheric carbon into rock reservoirs is examined through the lens of Urey reactions and the efficiency of carbon deposition in the continental crust reservoir (Kellogg et al., 2019); the authors argue that carbon stored in Earth's continental crust could have been extracted either from the early atmosphere or from the mantle (over a longer period of time) or both. Kellogg et al. (2019) challenge the community to prioritize better constraints on the concentration of carbon in the atmosphere and continental crust over geologic time. Their work also addresses the recovery (relaxation time) of Earth's climate to volcanically-forced climate change, using the Paleocene-Eocene thermal maximum as a case study; the calculated relaxation time is $\sim 50,000$ years. This timeframe is certainly of modern concern, given anthropogenic injections of carbon into the atmosphere.

Shales are known to be large carbon sinks in low pressure settings. Basu et al. (2019) ask whether shales can retain significant carbon during low pressure-temperature and high pressure-temperature processes during the subduction of Earth's crust. In a custom-built high vacuum line, they incrementally heat shale samples from 200 to $1,400^{\circ} \mathrm{C}$ in the presence of $\mathrm{O}_{2}$ gas and record the carbon and nitrogen abundances, $\delta^{13} \mathrm{C}$ values, and the atomic $\mathrm{C} / \mathrm{N}$ ratios for the gas at each stage of heating. Basu et al. (2019) propose that carbon silicate minerals, biomineralized and/or occluded, can be efficiently retained as a refractory phase and transferred into Earth's mantle through subduction.

The important role of serpentinization is emphasized in this context also: Barbier et al. (2020) offer a detailed review of hydrogen, methane, and hydrocarbon formation through experimental serpentinization, informed by network analysis. The relevance of the frequently invoked Fischer-Tropsch-type (FTT) reactions to produce methane from the abiotic reduction of oxidized carbon by $\mathrm{H}_{2}$ is questioned. Barbier et al. (2020) follow the forms and movement of carbon through the near ubiquitous, extensive serpentinization process, operating beneath most past and present seabeds.

Carbon cycling mediated by the deep biosphere is tracked also, in terms of function, detection, and novel findings. The deep mine microbial observatory in south Dakota, United States, described by Osburn et al. (2019), is a stable portal to the continental deep subsurface, with a rich, initial database on which future studies can pivot. In the marine realm, Cario et al. (2019) offer a perspective on the state of the science exploring the deep biosphere beneath the seabed. Aspects of the growth and resilience of subseafloor crustal biofilms are documented (Ramirez et al., 2019), and methods enabling new discernment of virus abundance in the subseafloor sedimentary blanket are shared (Pan et al., 2019). A new serpentinite-influenced

\section{REFERENCES}

Barbier, S., Huang, F., Andreani, M., Tao, R., Hao, J., Eliesh, A., et al. (2020). A review of $\mathrm{H} 2, \mathrm{CH} 4$, and hydrocarbon formation in experimental organism, Petrocella atlantisensis, cultured from Atlantis Massif oceanic core complex rocks sampled during IODP Expedition 357 is described, observed at controlled hydrostatic pressure (Quemeneur et al., 2019).

The findings reported in deep carbon science underscore the need for multidisciplinary commitment to open questions related to Earth's carbon cycle. It is clear that the processes driven by, and driving, plate tectonics buffer the carbon fluxes on which life has been dependent for billions of years (e.g., fluctuations in atmosphere-ocean geochemistry). Important work includes methodical application of current techniques, but much work requires new ways of thinking: multifaceted investigations that connect the deep and shallow biospheres, and/or describe links between the whole biosphere and points of contact with geosphere have the potential to transform our thinking. The breadth of disciplines and scientific approaches collated in deep carbon science provides exciting insight into a future where the traditional boundaries of classic disciplines become blurred. This, we argue, is the only way to reveal the true nature and extent of carbon cycle phenomena that are both vast and diminutive, slow yet fast, known but inaccessible, and everywhere all at once.

\section{AUTHOR CONTRIBUTIONS}

DC drafted a first version of this editorial. All authors contributed to and approved the final version.

\section{FUNDING}

SZ was supported by Australian Research Council grant IH130200012, a University of Sydney Robinson Fellowship, and Alfred P. Sloan grants G-2017-9997 and G-2018-11296.

\section{ACKNOWLEDGMENTS}

This research topic developed under the auspices of the Deep Carbon Observatory, whose continuous support led to profound changes in our understanding of the connections between fast and slow, shallow and deep, modern and ancient processes undergone by carbon in its various forms. DB acknowledges Swiss National Science Foundation (SNSF) Ambizione Grant 173992. DC acknowledges the support of the NASA Astrobiology Institute (Cooperative Agreement NNA15BB02A). MP acknowledges the support of the Swiss National Science Foundation (Ambizione Fellowship PZ00P2_168166) and the UGA Presidential Funds.

serpentinization using network analysis. Front. Earth Sci. 8, 209. doi:10 3389/feart.2020.00209

Basu, S., Verchovsky, A. B., Bogush, A., Jones, A. P., and Jourdan, A.-L. (2019). Stability of organic carbon components in shale: implications for carbon cycle. Front. Earth Sci. 7, 297. doi:10.3389/feart.2019.00297 
Cario, A., Oliver, G. C., and Rogers, K. L. (2019). Exploring the deep marine biosphere: challenges, innovations, and opportunities. Front. Earth Sci. 7, 225. doi:10.3389/feart.2019.00225

Dong, J., Li, J., and Zhu, F. (2019). Wetting behavior of iron-carbon melt in silicates at mid-mantle pressures with implications for Earth's deep carbon cycle. Front. Earth Sci. 7, 268. doi:10.3389/feart.2019.00268

Eickenbusch, P., Takai, K., Sissman, O., Suzuki, S., Menzies, C., Sakai, S., et al. (2019). Origin of short-chain organic acids in serpentinite mud volcanoes of the Mariana convergent margin. Front. Microbiol. 10, 1729. doi:10.3389/fmicb. 2019.01729

Hughes, E. C., Mazot, A., Kilgour, G., Asher, C., Michelini, M., Britten, K., et al. (2019). Understanding degassing pathways along the 1886 tarawera (New Zealand) volcanic fissure by combining soil and lake $\mathrm{CO} 2$ fluxes. Front. Earth Sci. 7, 264. doi:10.3389/feart.2019.00264

Kellogg, L. H., Turcotte, D. L., and Lokavarapu, H. (2019). On the role of the Urey reaction in extracting carbon from the earth's atmosphere and adding it to the continental crust. Front. Astron. Space Sci. 6, 62. doi:10.3389/fspas. 2019.00062

Merdith, A. S., Atkins, S. E., and Tetley, M. G. (2019). Tectonic controls on carbon and serpentinite storage in subducted upper oceanic lithosphere for the past 320 ma. Front. Earth Sci. 7, 332. doi:10.3389/feart.2019.00332

Morrison, S. M., Buongiorno, J., Downs, R. T., Eleish, A., Fox, P., Giovannelli, D., et al. (2020). Exploring carbon mineral systems: recent advances in $\mathrm{C}$ mineral evolution, mineral ecology, and network analysis. Front. Earth Sci. 8, 208. doi:10.3389/feart.2020.00208

Osburn, M. R., Kruger, B., Masterson, A. L., Casar, C. P., and Amend, J. P. (2019). Establishment of the deep mine microbial observatory (DeMMO), South Dakota, USA, a geochemically stable portal into the deep subsurface. Front. Earth Sci. 7, 196. doi:10.3389/feart.2019.00196

Pan, D., Morono, Y., Inagaki, F., and Takai, K. (2019). An improved method for extracting viruses from sediment: detection of far more viruses in the subseafloor than previously reported. Front. Microbiol. 10, 878. doi:10.3389/ fmicb.2019.00878

Quéméneur, M., Erauso, G., Frouin, E., Zeghal, E., Vandecasteele, C., Ollivier, B., et al. (2019). Hydrostatic pressure helps to cultivate an original anaerobic bacterium from the Atlantis Massif subseafloor (IODP expedition 357): Petrocella atlantisensis gen. Nov. sp. nov. Front. Microbiol. 10, 1497. doi:10. 3389/fmicb.2019.01497

Ramírez, G. A., Garber, A. I., Lecoeuvre, A., D’Angelo, T., Wheat, C. G., and Orcutt, B. N. (2019). Ecology of subseafloor crustal biofilms. Front. Microbiol. 10, 1983. doi:10.3389/fmicb.2019.01983

Sanloup, C., Hudspeth, J. M., Afonina, V., Cochain, B., Konôpková, Z., Lelong, G., et al. (2019a). Polymerized 4-fold coordinated carbonate melts in the deep mantle. Front. Earth Sci. 7, 72. doi:10.3389/feart.2019.00155

Sanloup, C., Hudspeth, J. M., Afonina, V., Cochain, B., Konôpková, Z., Lelong, G., et al. (2019b). Corrigendum: polymerized 4 -fold coordinated carbonate melts in the deep mantle. Front. Earth Sci. 7, 155. doi:10.3389/feart.2019.00155

Wong, K., Mason, E., Brune, S., East, M., Edmonds, M., and Zahirovic, S. (2019). Deep carbon cycling over the past 200 million years: a review of fluxes in different tectonic settings. Front. Earth Sci. 7, 263. doi:10.3389/feart.2019.00263

Conflict of Interest: The authors declare that the research was conducted in the absence of any commercial or financial relationship that could be construed as a potential conflict of interest.

Copyright (c) 2020 Cardace, Bower, Daniel, Ionescu, Mikhail, Pistone and Zahirovic. This is an open-access article distributed under the terms of the Creative Commons Attribution License (CC BY). The use, distribution or reproduction in other forums is permitted, provided the original author(s) and the copyright owner(s) are credited and that the original publication in this journal is cited, in accordance with accepted academic practice. No use, distribution or reproduction is permitted which does not comply with these terms. 